\title{
Influence of Intrinsic Permeability on the Production Perfor- mance of Shenhu Hydrate Sediment through Depressurization
}

\author{
Yingrui Ma, Shuxia $\mathrm{Li}^{*}$, and Wu Didi \\ School of Petroleum Engineering, China University of Petroleum (East China), Qingdao 266580, Shandong Province, People’s Republic \\ of China
}

\begin{abstract}
Natural gas hydrate(NGH) is a clean resource with huge reserves. The depressurization method is an economical and effective exploitation method. In the process of depressurization, reservoir absolute permeability has an important influence on production results. Based on the data of Shenhu hydrate reservoirs, this paper established a depressurization production numerical simulation model. Then, the production performances such as pressure, temperature, gas production rate, cumulative gas production, and hydrate dissociation effect are all studied under different permeability conditions.study the change of reservoir pressure, gas production rate, cumulative gas production, reservoir temperature change and hydrate dissociation effect under different permeability conditions. Results show that higher permeability is conducive to the depressurization of hydrate reservoirs.
\end{abstract}

\section{Introduction}

Natural gas hydrate has attracted much attention of many countries, because of its many advantages. Such as: high energy efficiency, huge reserves and low pollution characteristics[1]. The methods that have been suggested to exploiting NGH from hydrate bearing are depressurization, thermal stimulation, inhibitor injection, carbon dioxide replacement and solid fluidization. Among which the depressurization method does not need expensive heat injection equipment and its process is simple. It is considered to be the most economical and feasible development method[2]. The currently exploitation by depressurization in the sea regions of Nankai Trough off, South China Sea, Mackenzie Delta (CAN) and Siberia (RUS)[3-5].

At present, scholars have done many studies on hydrate exploitation by depressurization. $\mathrm{Su}$ et al. established a mathematical model of hydrate dissociation, and evaluated the production potential of Shenhu hydrate reservoir. The result showed that the depressurization production is mainly affected by production pressure[6]. Bai et al. used experimental and numerical simulation methods to study the dissociation of hydrate in reservoir and the result showed that production pressure has an important influence on the dissociation of hydrates. In the absence of icing, the lower the bottom hole pressure is, the higher the gas production is. In the presence of ice, lower bottom hole pressure may not be conducive to improving gas productivity[7]. Zhao et al. studied the temperature change during the dissociation process of hydrate by numerical simulation. Ji et al. studied depressurization process by numerical simulation and the results shows that permeability has an important influence on heat transfer and hydrate dissociation front movement rate[8]. Haligva et al. studied the production characteristics of natural gas hydrate by depressurization experiments. The results show that higher pressure reduction range has higher initial gas production rate and cumulative gas production[9].

In summary, the research of scholars mainly focused on effectiveness of hydrate depressurization, influence of production conditions and characteristics of depressurization, but the research of production characteristic by reservoir permeability is less. Geological conditions of actual reservoirs are complex and reservoir permeability plays an important role in the exploitation of NGH. The hydrate reservoir in Shenhu area of China is composed of single hydrate reservoir and impermeable upper and lower burdenrock. Shenhu hydrate reservoir has low permeability and poor mobility.

This paper studied the gas production effect of different permeability by numerical simulation method.

\section{Shenhu hydrate model}

According to the mechanism of gas hydrate dissociation, establishing a three-dimensional model of Shenhu hydrate reservoir. The model involves three phases (gas phase, hydrate phase and water phase) and three components (methane, hydrate and water). Gas water two phase flow follows Darcy' Law. The mathematical model for hydrate dissociation in porous media, which includes mass conservation equation, energy conservation equation, hydrate dissociation kinetics equation and auxiliary equation[10-15].

Based on the geological data of Shenhu hydrate reservoir, the size of the base model is $500 \mathrm{~m} \times 500 \mathrm{~m} \times$

\footnotetext{
$\overline{{ }^{*} \text { Corresponding author: lishuxia@upc.edu.cn }}$
} 
$90 \mathrm{~m}$, and the plane is divided into $25 \times 25$ grids. Each grid size is $20 \mathrm{~m} \times 20 \mathrm{~m} \times 30 \mathrm{~m}$. The $30 \mathrm{~m}$ hydrate layer is vertically divided into 15 grids so the thickness of each layer is $2 \mathrm{~m}$. Fig. 1 shows the geological model of Shenhu hydrate reservoir. The thickness of the upper burden layer and the lower burden layer are both $30 \mathrm{~m}$. The upper and lower burden layers are meshed in the same manner as the hydrate layer. There is no material exchange between the burden layer and the hydrate layer, but energy exchange. Table 1 . shows the model parameter of Shenhu hydrate reservoir.

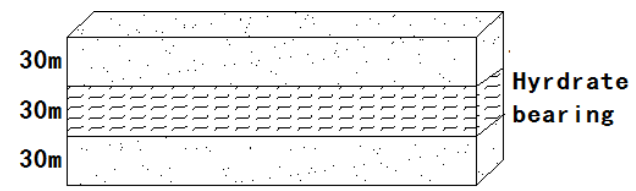

Fig. 1. Geological model of hydrate reservoirs in Shenhu area

Table 1. Fundamental parameters of Shenhu hydrate reservoir

\begin{tabular}{|c|c|}
\hline Parameter & Value \\
\hline Water depth $H$ & $1273.8 \mathrm{~m}$ \\
\hline reservoirdepth $L$ & $220 \mathrm{~m}$ \\
\hline overburden thickness $\Delta \mathrm{Z}_{\mathrm{O}}$ & $30 \mathrm{~m}$ \\
\hline HBL thickness $\Delta \mathrm{Z}_{\mathrm{H}}$ & $30 \mathrm{~m}$ \\
\hline underburden thickness $\Delta \mathrm{Z}_{\mathrm{U}}$ & $30 \mathrm{~m}$ \\
\hline Initial pressure $P$ & $14.14 \mathrm{MPa}$ \\
\hline Initial temperature $T$ & $14.2^{\circ} \mathrm{C}$ \\
\hline Initial porosity $\varphi$ & 0.33 \\
\hline Rock specific heat $C_{\mathrm{R}}$ & $1000\left(\mathrm{~J} \bullet \mathrm{kg}^{-1} \cdot{ }^{\circ} \mathrm{C}^{-1}\right)$ \\
\hline Rock thermal conductivity $\lambda_{R}$ & $338700 \mathrm{~J} \cdot \mathrm{m}^{-1} \cdot \mathrm{d}^{-1} \cdot{ }^{\circ} \mathrm{C}^{-1}$ \\
\hline Initial hydrate saturation $S_{\mathrm{h}}$ & 0.4 \\
\hline Initial water saturation $S_{\mathrm{w}}$ & 0.6 \\
\hline Initial gas saturation $S_{\mathrm{g}}$ & 0 \\
\hline Burdenillary force model & $P_{c a p}=-P_{o}\left[\left(S^{*}\right)^{-\frac{1}{\lambda_{c}}}-1\right]^{1-\frac{1}{\lambda_{c}}}$ \\
\hline$P_{\mathrm{o}}$ & $0.1 \mathrm{MPa}$ \\
\hline$\lambda_{\mathrm{c}}$ & 0.45 \\
\hline Relative permeability model & 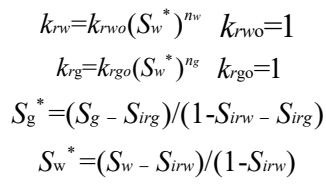 \\
\hline$S_{\text {irw }}$ & 0.3 \\
\hline$S_{\text {irg }}$ & 0.05 \\
\hline$n_{\mathrm{w}}$ & 3 \\
\hline$n_{\mathrm{g}}$ & 3 \\
\hline Absolute permeability model & $K(\phi)=K_{0} \cdot\left(\frac{\phi}{\phi_{0}}\right)^{c k} \cdot\left(\frac{1-\phi_{0}}{1-\phi}\right)^{2}$ \\
\hline$c k$ & 5 \\
\hline
\end{tabular}

\section{Results and discussion}

This paper mainly studies the production effect under different permeability $\mathrm{K}_{0}$. Through investigating the data of Shenhu hydrate reservoir, results show that the permeability of Shenhu hydrate reservoir is between $1 \sim 10 \mathrm{mD}$. Therefore, 6 cases with different permeability are designed, which is shown in Table 2[16].
Table 2. Reservoir permeability of different cases.

\begin{tabular}{|c|c|}
\hline Case & $\begin{array}{c}\text { Permeability } \\
\mathbf{K}_{\mathbf{0}} / \mathbf{m D}\end{array}$ \\
\hline Case 1 & 1 \\
\hline Case 2 & 2 \\
\hline Case 3 & 4 \\
\hline Case 4 & 6 \\
\hline Case 5 & 8 \\
\hline Case 6 & 10 \\
\hline
\end{tabular}

\subsection{Effect on Reservoir Pressure}

Fig. 2 shows the variation of average reservoir pressure vs. time in different cases. The change trend of average pressurein six cases is similar. The process can be divided into the following stages: First, the pressure decline sharply as the production of free water. Then, the hydrate dissociates gruadually so that the gas and water are released slowly. Finally, due to the complete dissociation of the hydrates in the reservoir, the reservoir pressure is almost stable. Fig. 3 shows the pressure distribution in the middle of the reservoir at 3000 days in different cases. It can be seen that there pressure fronts, which spread form bottom hole. The pressure front of case 5 and case 6 have spread to the model boundary at 3000 days, so the pressure front is not visible.

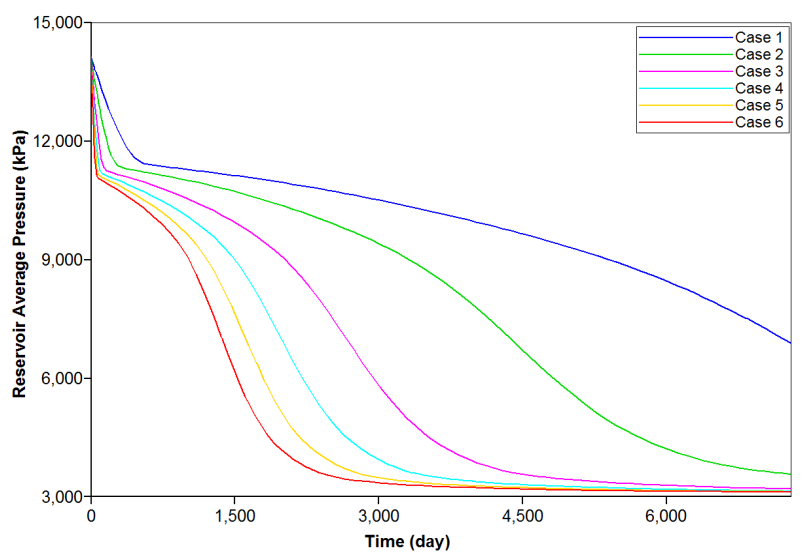

Fig. 2. Average pressure vs. time in different permeability cases ( 7305 days)

\subsection{Effect on gas production}

Figure 4 shows gas productivity and cumulative gas production in different cases. It can be found that the gas production process can be divided into three stages: First, the reservoir pressure decreases but is still than equilibrium pressure. The gas production rate is 0 . Then, with the development go forward, the reservoir pressure is lower than the phase equilibrium pressure which causes hydrate beginning to dissociate. With the dissociation of NGH, porosity and permeability increase, which leads to gas production rate improved. Finally, the gas production rate decreases gradually after reaching the maximum value. With the increase of reservoir permeability, the initial gas recovery rate is faster. And it costs less time in reaching the maximum gas production rate. In 7305 days of simulation, cumulative gas 
production of case 4, case 5 and case 6 is relatively high. And the results of these cases are similar. On account of the low permeability of case 1 , the reservoir pressure is relatively high. The pressure decrease slowly and leading to the low cumulative gas production ultimately.
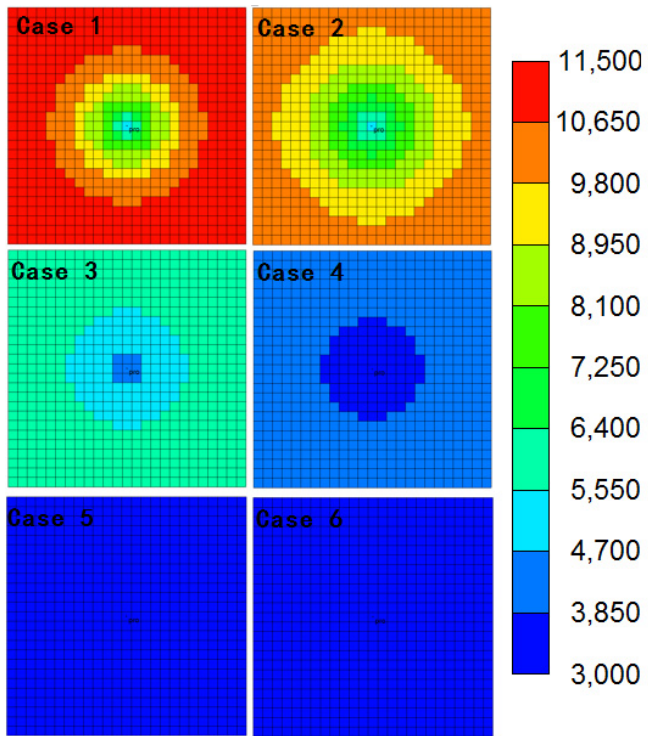

Fig. 3. Planar pressure distribution in the middle of reservoir under different cases (3000 days)

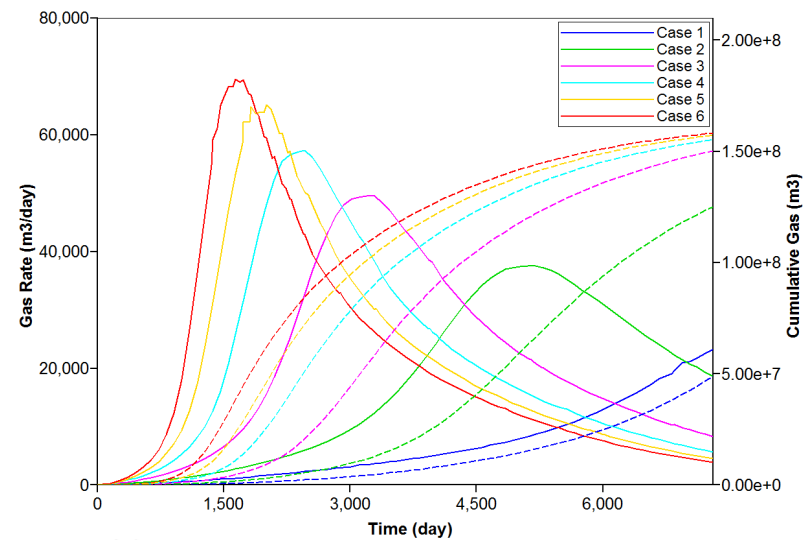

Fig. 4. Gas production rate and cumulative gas production in different cases ( 7305 days)

\subsection{Effect on reservoir temperature}

Fig. 5 shows the average temperature variation of reservoirs in different cases. The temperature variation trends of six different cases are similar and it can be divided into three stages as follows: First, in the initial stage of exploitation, free water in reservoir is extracted, hydrate does not dissociate and reservoir temperature remains unchanged, because reservoir pressure is higher than phase equilibrium pressure. Then, with the development go forwardas development progresses, when reservoir pressure is lower than phase equilibrium pressure, the hydrate begins to dissociate, and the dissociation rate of hydrate increases gradually in the early stage of development. The heat absorbed by hydrate dissociation increases gradually. The average temperature of the reservoir dropped rapidly. In the later stage, the heat absorbed by the hydrate dissociation is reduced due to the decrease in of hydrate saturation. The average temperature of the reservoir decreases slowly. Fig. 6 shows the planar temperature distribution in the middle of reservoir under different cases. It can be seen intuitively that reservoir temperature decreases with the decrease of hydrate saturation. The results show that the higher the permeability, the faster the cooling rate of the reservoir. Moreover, While the reservoir temperature at the same location is lower. However, the heat provided by the upper and lower burden layerscap rocks and the heat absorbed by hydrate dissociation increase, so the temperature plane distribution in the same case has little difference.

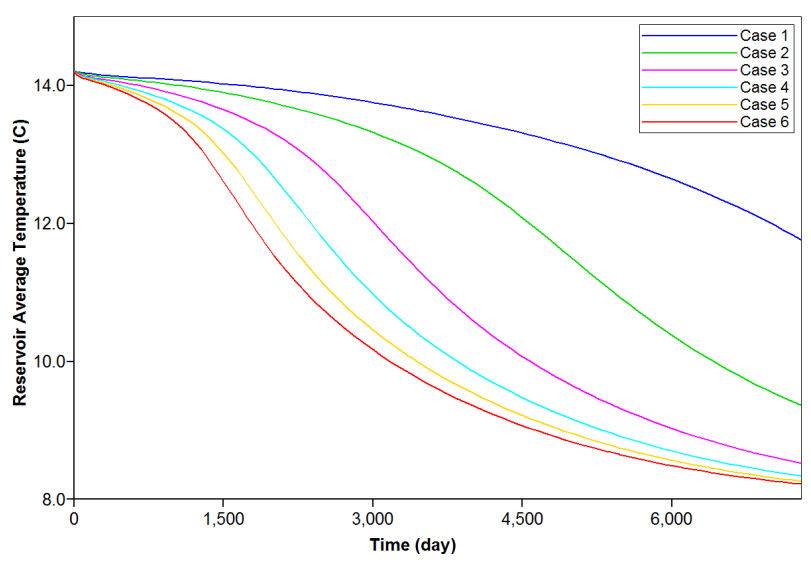

Fig. 5. Average temperature of reservoir in different cases (7305 days).

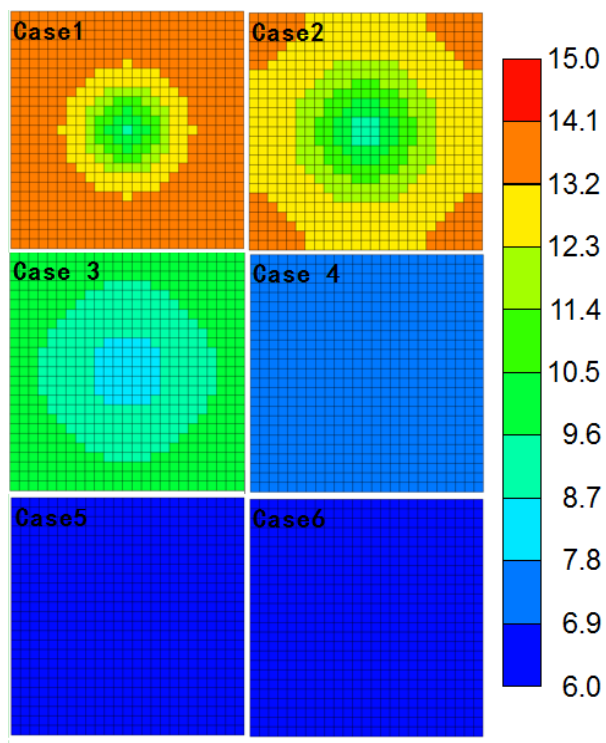

Fig. 6. Planar temperature distribution in the middle of reservoir under different cases (3000 days).

\subsection{Effect on reservoir hydrate saturation}

Fig. 7 shows the variation of reservoir hydrate volume in different cases. The trend of 6 cases are similar. In the early stage of exploitation, due to the dissociation of hydrate, $\mathrm{t}$ the decompression depressurization effect is gradually enhanced. Therefore, the decline rate of average hydrate saturation decline rate of the reservoir is 
gradually increasing. At the later stage, the saturation of the hydrate keeps low. The reason is that the dissociation rate of hydrate decreases. In the case of low permeability $(1 \sim 2 \mathrm{mD})$, the dissociation rate of hydrate is slower and their dissociation trends are quite different from other cases.

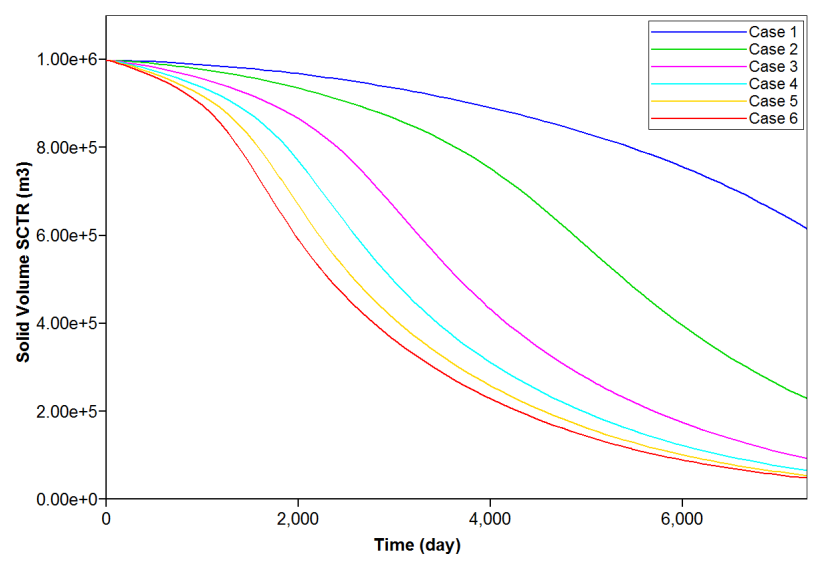

Fig. 7. Hydrate volume of reservoir in different cases (7305 days).

\section{Conclusion}

(1) High permeability is benefital to the flow of gas and water in reservoirs, the movement of pressure front is promoted and the average reservoir pressure decreases faster.

(2) The saturation of hydrate reservoir decrease quickly under the high permeability condition. And the energy absorbed by hydrate dissociation is mainly supplied by the hydrate layer and the top-bottom layers. So the average temperature of hydrate reservoir decreases quickly under the high permeability condition.

(3) Gas production rate is higher under the condition of high permeability. And it can reach the peak quickly. When the permeability is high $(6 \sim 10 \mathrm{mD})$, the cumulative gas production of several cases is similar. When the reservoir permeability is low, the effect of depressurization is not obvious. So the method of reservoir permeability modification can be carried out to increase the hydrate dissociation and gas productivity.

\section{References}

1. Y. Wang, J.C. Feng, , X.S. Li, Y. Zhang, G. Li, (2015). Analytic modeling and large-scale experimental study of mass and heat transfer during hydrate dissociation in sediment with different dissociation methods.Energy, 90, 1931-1948.

2. X.S. Li, C.G. Xu, Y. Zhang, X.K. Ruan, G. (2016).Investigation into gas production from natural gas hydrate: A review.Applied Energy, 172, 286-322.

3. K.U. Heeschen, S. Abendroth, M. Priegnitz, E. Spangenberg, J. Thaler, J.M. Schicks, (2016).Gas production from methane hydrate: A laboratory simulation of the multistage depressurization test in
Mallik, Northwest Territories, Canada.Energy \& Fuels, 30(8), 6210-6219.

4. S. Zhou, J. Zhao, Q. Li, W. J. Chen, (2018).Review on natural gas hydrate in 2017.Science \& Technology Review 36(1), 83-90.

5. W. Wei, J.H. Zhang, R.Z. Yu, B.B. Lin, L.Q. Chen, Y. Peng, (2016).Evaluation of gas production potential from gas hydrate deposits in National Petroleum Reserve Alaska using numerical simulations. Journal of Natural Gas Science and Engineering, 36, 760-772.

6. Z. Su, L. Huang, N. Wu, S. (2010).Evaluation of gas production potential from marine gas hydrate deposits in Shenhu area of South China Sea.Energy \& Fuels, 24(11), 6018-6033.

7. Y. Bai, Q. Li, X. Li, \& Y. Du, (2008). The simulation of nature gas production from ocean gas hydrate reservoir by depressurization. Science in China Series E: Technological Sciences, 51(8), 1272.

8. J. Zhao, Z. Zhu, Y. Song, W. Liu, (2016). Sustainable gas production from methane hydrate reservoirs by the cyclic depressurization method. Energy conversion and management, 108, 439-445.

9. Y. Konno, Y. Masuda, K. Akamine, (2016). Influence of reservoir permeability on methane hydrate dissociation by depressurization. International Journal of Heat and Mass Transfer, 103, 265-276.

10. J. Zhao, Z. Fan, H. Dong, Z. Yang, Y. Song, (2016). Influence of reservoir permeability on methane hydrate dissociation by depressurization. International Journal of Heat and Mass Transfer, 103, 265-276.

11. M. Terzariol, G. Goldsztein, J.C. Santamarina, (2017). Maximum recoverable gas from hydrate bearing sediments by depressurization. Energy, 141, 1622-1628.

12. C. Haligva, P. Linga, J.A. P. Ripmeester, (2010).Numerical simulation for laboratory-scale methane hydrate dissociation by depressurization. Energy Conversion and Management, 51(10), 18831890.

13. H. Liang, Y. Song, Y. Chen, (2011).The use of huff and puff method in a single horizontal well in gas production from marine gas hydrate deposits in the Shenhu Area of South China Sea. Journal of petroleum science and engineering, 77(1), 49-68.

14. X. Jiang, S. Li, L. Zhang, (2012). Sensitivity analysis of gas production from Class I hydrate reservoir by depressurization. Energy, 39(1), 281285.

15. G. Li, G.J. Moridis, K. Zhang, X.S. Li, Effect of thermal stimulation on gas production from hydrate deposits in Shenhu area of the South China Sea.Science China Earth Sciences, 56(4), 601-610.

16. J.F. Li, J.L. Ye, X.W. H.J, Qin, (2018).The first offshore natural gas hydrate production test in South China Sea.China Geology, 1(1), 5-16. 